\title{
Strategies of Avoiding Medicolegal Problems
}

\author{
Pankaj R. Patel ${ }^{1}$
}

"Medicine is of all the arts the most noble, but owing to ignorance of those who practice it, and those who, inconsiderately form a judgment of them, it is at present far

behind all other arts." Hippocrates

The provision of unnecessary health care is a serious problem and involves two key legal issues. First, doctors' fear of litigation drives defensive practices - ordering tests and procedures, making referrals, and prescribing drugs to reduce perceived legal risks, rather than to advance patient care. Second, suboptimal communication and decision-making processes undermine a patient's right to make informed health-care choices [1]. Information is available to judge and evaluate with limited knowledge in the field. Do we feel the same thing nowadays? Probably yes; and before consulting a patient, medicolegal implications are the first fear in our mind due to some of the facts such as decline in self-regulatory standards, rise in medical malpractices and commercialization, imbalance between service and business, and lack of an effective internal or external regulation. We must not forget the truth that there is a public outcry against medical profession due to some incidences, which is generally being applied to all healthcare professional community by media because of negative coverage. We should also remember that this is not the commonest issue in each doctor's career; and media are not always negative, however, only a few incidences will imprint a general impression on the mindset of public and end up in to medicolegal consequences. We must come out of this fear and phobia and succeed in career if we maintain an acceptable standard of care and communication.

If we discuss about the difference of medicolegal problems between physicians and surgeons, it is found that surgeons receive complaints twice as much as received by physicians [2]. This increased risk of litigation arises partly from involvement

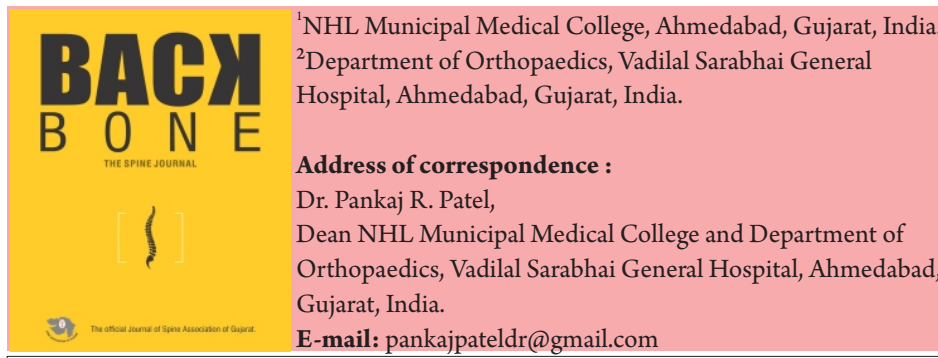

(C) 2020 | Back Bone: The Spine Journal (The Official Journal Of "Spine Association Of Gujarat") | Available on www.backbonejournal.com | doi:10.13107/bbj.2020.v01i01.003 This is an Open Access article distributed under the terms of the Creative Commons Attribution Non-Commercial License (http://creativecommons.org/licenses/by-nc/3.0) which permits unrestricted noncommercial use, distribution, and reproduction in any medium, provided the original work is properly cited. in surgical procedures and treatments but also reflects wider concerns about interpersonal skills, professional ethics, and substance use. Improved understanding of these patterns may assist efforts to reduce harm and support safe practice. Medical negligence is a very commonly heard when a patient or their relative files a litigation case against any doctor or hospital since the medical profession is considered as service, not a profession and patient is considered as a customer. In 1995, the Supreme Court's decision in Indian Medical Association versus V P Shantha brought the medical profession within the ambit of a "service" as defined in the Consumer Protection Act, 1986. This defined the relationship between patients and medical professionals as contractual [3]. In simple words, medical negligence is doing a thing that other doctor would not do (i.e., commission, etc.) or not doing something that the other doctor would do (i.e., omission, etc.). It can be applied if practices acceptable to medical profession of the newer methods or more skilled doctors are available. Therefore, it is imperative for all of us to maintain evidence-based ethical practice, and thereby, remaining away from medical negligence. We should remember that, the Honorable court would consider those issues in case such as, Res Ipsa Loquiter means thing that speaks itself, the expert evidence if present, medical records of the hospital, available medical literature, and postmortem in case of mortality.

"Man may tell lie but documents would not." This would definitely apply when we treat a patient, and therefore, maintenance of medical record is must to avoid any kind of medicolegal consequences. Remember it is the doctor's or hospital's responsibility to maintain and preserve records, not patient's. The medical record and other documentation from the treating doctor or hospital generally speak truth. It is generally prepared at the time of presentation in outpatient, emergency, or wards. It is considered as unbiased, objective, and independent evidence in case of any dispute. It also reflects the real condition of patient at different times of management. It exhibits the overall gravity of the condition and outcome. Therefore, it is mandatory to document complete diagnosis, ways of management, and possible complications in the record. There should not be correction afterward that becomes obvious. Inpatient records considered are daily visit 
notes, surgical notes, anesthetist notes, other references notes, prescriptions with details of medicines with their proper dose and schedule, daily clinical parameter charts, laboratory and radiological investigations reports, daily progress or deterioration reports, etc. It is also advisable to have computerized reports in electronic medical record, which can be reproducible. The treating doctor must sign all documents, certificates, and daily notes including discharge papers.

The former President of United States Mr. Abraham Lincon said, "No man is good enough to govern another man without the other's consent." Informed and signed consent is mandatory document in case of interventional procedure or surgery. "Informed consent" is defined as consent that is given by a person after receipt of following information: The nature and purpose of the proposed procedure or treatment; the expected outcome and likelihood of success and risks; the alternative to the procedure and supporting information regarding those alternatives; and the effect of no treatment or procedure including its effect on prognosis and instructions concerning what should be done if the procedure turns out to be harmful or unsuccessful. It is mandatory to inform and take separate consent if procedure is two or more stages or two or even more surgical approaches. Consent should also be repeated if any additional procedure is to be done. In medical law, consent taken for diagnostic procedure cannot be considered as authorization or permission to perform therapeutic procedure such as angiography and angioplasty. Sometimes, it is also practiced taking an audiovisual consent in case of vulnerable or emergency patients and specially in research subjects in clinical trials. However, it is neither the routine practice nor it is mandatory at present. Another possible explanation for a higher risk of medicolegal problems in a surgical case is that surgeons administer the riskiest treatments to the sickest patients; and therefore, easily observable poor outcomes go with the territory [4]. Therefore, it up to the surgeon to decide or involve further opinion before implementing risky surgeries in a high-risk patient.

Tibble et al. found systematic differences in complaints about other issues, including communication and interpersonal behavior in cases of surgeons who were challenged mediolegally [2]. Recent research into discrimination and bullying in the surgical profession found that these behaviors are "pervasive and serious problems in the practice of surgery" [5]. Therefore, it is understood that poor communication between doctor and patient is a prime factor behind majority of the medicolegal cases, which results into unfolding of various documentation errors. It is commonly observed that a surgeon with an excellent communication skill with an average clinical skill excels in his/her career; and on the other hand, a surgeon with poor communication skill with an extraordinary clinical skill often has a turbulent career path. We have also seen that a patient with multiple complications during the treatment often turns out to be your best and loyal customer who also refers more patients to you. While, on the other hand, the patient who has an excellent outcome and better than expected results may not recommend your name in a similar case. The only reason is communication. Therefore, importance of communication ideally should come before documentation. Communication should be frequent and interactive between doctor and patient with the relatives as well. Communication should always be two-sided rather than one-sided especially doctor giving information without giving patient an opportunity to ask. Explanation of all events must be discussed on regular basis and during visits as well. Practitioner should himself face the patient and the family in case of any event, complication, or poor prognosis rather than sending the information through a junior colleague or staff that create a fear and anger component in the patient's mind. The duty of a clinician is to provide confidence and trust with actual facts in a patient and family while treating. In addition, document your communication for future purpose as well with dually signed by the doctor and patient. I would like to say there are four things to avoid medicolegal problems in a surgeon's life by enlarge: Communication, Documentation, Communication of documentation, and Documentation of communication. I think we must follow this principle into our own practice whether it is done at a government or private place, other colleague's referral place, our own clinic, or even on teleconsultation.

The remainder of the difference arose from surgeons' higher risk of complaints across a range of issues: Surgeons have complaint rates that are more than 1.5 times as high as physicians in relation to monitoring and follow-up, fees and fraud, reports and certificates, substance use, communication, and interpersonal behavior. Surgeons were at a lower risk in relation to prescribing $[2,4]$. Among surgeons, male sex, older age, and practice in regional or remote areas are also risk factors for complaints, as were practice in orthopedics, neurosurgery, and plastic surgery. The previous studies have shown worrying levels of alcohol misuse and burnout among surgeons $[6,7]$. These should be better explained by following the ethical code of conduct in case of medical profession. When a patient decides for filing a case against the doctor, his surrounding environment thinks that the first is "High fees and poor care" including the media conversation. Therefore, in recent times, the suggestion is to have a lenient view of finances in a really needy patient, however, it should not be a waiver which gives in fact a negative message regarding doctor's mistake resulted in to fees waiver. In addition, there should not be too much downgrading of the treatment cost which indirectly indicates the initial quotation as inflated or wrong. In addition, we should not hesitate handing over the hospital records or 
documents including other colleague's opinion, especially in case of a complication, technically challenging case or a highrisk case. Such behavior in fact infuses confidence in the mind of patient and proves transparency from clinician's end. It also infuses the trust when we keep back up literature support with an effective communication with explanation of standard care of treatment while discussing treatment options. We must not forget mentioning that we need to treat patient not the radiology reports or laboratory reports, which indirectly attract patient toward the clinician. In addition, doctor must be a good listener to his/her patient. If you listen to your patient carefully with proper attention, you will better understand the actual problem and requirement, which indirectly help in prescribing the correct treatment.
Finally, we must remember the words by the greatest scientist Mr. Albert Einstein, "Any man who reads too much and uses his own brain too little, falls into lazy habits of thinking." Therefore to avoid medicolegal problems in a medical profession is to use our common senses (brain) and implementing techniques of communication with patience while listening to patient's (customer's) problem, documenting all his/her problems with both way agreement, maintain and handling all records up to date, remaining in current world with recent literature, facing any complication and showing responsibility on your end for further plans yourself and being lenient regarding financial aspects especially self-paying patients.

I acknowledge the kind help from Dr. Hitesh Modi and Dr. Bharat Dave for preparing this article for the publication in the journal.

\section{References}

1. Ries NM. Choosing wisely: Law's contribution as a cause of and a cure for unwise health care choices. JLaw Med 2017;25:210-28.

2. Tibble HM, Broughton NS, Studdert DM, Spittal MJ, Hill N, Morris JM, et al. Why do surgeons receive more complaints than their physician peers? ANZJ Surg 2018;88:269-73.

3. Supreme Court of India. Indian medical association vs V.P. Shentha. Judgem Inform Syst 1995;6:651.

4. McNamara S. Surgeons top Multiple Complaints List. United States: MJA InSight; 2011.p.24.

Conflict of Interest: NIL Source of Support: NIL

Source of Support: NIL
How to Cite this Article

Patel PR| Strategies of Avoiding Medicolegal Problems $\mid$ Back Bone: The Spine Journal October 2020-March 2021; 1(1):5-7.
5. Knowles $R$, et al. Expert advisory group on discrimination, bullying and sexual harassment: Report to RACS; 2015 . Available from: https://www.data.gwa.gov.au/datasets.html-part-1.

6. Oreskovich MR, Kaups KL, Balch CM, Hanks JB, Satele D, Sloan J, et al. Prevalence of alcohol use disorders among American surgeons. Arch Surg 2012;147:168-74.

7. Balch CM, Freischlag JA, Shanafelt TD. Stress and burnout among surgeons: Understanding and managing the syndrome and avoiding the adverse consequences. Arch Surg 2009; 144:371-6. 